This is a copy of the "Post-print" (i.e., the authors' final draft, post-refereeing). Published as:

Wang, C., Si, Y., Abdul-Rahman, H., \& Wood, L. C. (in press). Noise annoyance and loudness: Acoustic performance of residential buildings in tropics. Building Services Engineering Research and Technology.

\title{
Noise Annoyance and Loudness: Acoustic Performance of Residential Buildings in Tropics
}

\author{
Chen Wang ${ }^{1}$, Yuenxun $\mathrm{Si}^{2}$, Hamzah Abdul-Rahman ${ }^{3}$, Lincoln C. Wood ${ }^{4}$ \\ 1,2,Centre for Construction Innovation and Facility Management (CIFM), Faculty of Built Environment, University of \\ Malaya, 50603, Kuala Lumpur, Malaysia \\ 3,Faculty of Science Technology Engineering and Mathematics (STEM), International University of Malaya-Wales, \\ 50408, Kuala Lumpur, Malaysia \\ 4. Faculty of Business and Law, Auckland University of Technology, Auckland, New Zealand; and also Curtin Business \\ School, Curtin University, Bentley, Western Australia, Australia.
}

Corresponding Author: Assoc. Prof. Dr. Chen Wang

Email: derekisleon@gmail.com

Tel: 03-7967 6860

\begin{abstract}
Assoc. Prof. Dr. Chen Wang is an Associate Professor of Construction Innovation, Surveying, and Engineering Management in the Faculty of Built Environment, University of Malaya. He was a senior engineer of China State Construction Engineering Corporation (CSCEC), which is the main contractor of the 2008 Olympics Beijing National Aquatics Center known as "Water Cube". His research interests include Vertical Greenery System (VGS), Mathematics Modeling for Civil Engineering, swarm intelligence, Ant Colony Optimization (ACO), Fuzzy-QFD, Tensile Membrane Steel Structure, Vertical Greenery Systems, Repertory Grid, sustainability in construction management, international BOT projects, energy conservation, and building integrated solar application, supported by his vast publications. He is an IEEE member (U.S.), RICS member (U.K.), and also a perpetual member of The Chinese Research Institute of Construction Management (CRIOCM), Hong Kong (International).
\end{abstract}

Prof. Dr. Hamzah Abdul Rahman Dip.Bldg (UiTM), BSc.(Hons) Central Missouri State University, M.Sc. University of Florida, PhD University of Manchester Institute of Science and Technology, FRICS, MCIOB, MIVMM, is currently the Vice-Chancellor of the International University of Malaya-Wales(IUMW), which is one of the world's first Malaysia-British university among research led universities. He has served as the Deputy Vice Chancellor (Research \& Innovation), University of Malaya and a full professor in the Faculty of Built Environment, University of Malaya. He has served as the Deputy Vice Chancellor for Development and Estate Management in charge of development policies and construction projects from 1996 to 2003, and the Deputy Vice Chancellor (Academic \& International) from 2009-2010 in University of Malaya. He holds a $\mathrm{PhD}$ degree from the University of Manchester Institute of Science and Technology (UMIST, UK), M.Sc. from University of Florida and BSc. (Hons) from Central Missouri State University, Dip. Bldg (UiTM). His research interests include the construction innovation \& sustainability, green buildings, project \& facility management, building energy efficiency, industrialized building system (IBS), and renewable energy application in buildings, supported by his vast publications. He is also a fellow member of the Chartered Institute of Surveyors, United Kingdom (International).

Yuenxun Si is a research fellow of Construction Innovation, Surveying, and Engineering Management in the Faculty of Built Environment, University of Malaya. His expertise is in acoustic analysis and noise detection.

Dr. Lincoln C. Wood is a Senior Lecturer (operations and supply chain management) at Auckland University of Technology (New Zealand) and an Adjunct Research Fellow at Curtin Business School (Australia). He received the 2009 Council of Supply Chain Management Professional's (CSCMP) Young Researcher Award (Chicago, USA), serves on the editorial board of logistics, supply chain, and analytics journals, and serves on the committee in the Northern Section (NZ) for the Chartered Institute of Logistics and Transport. His research interests include operations and supply chain management in the construction industry, logistics, and gamification. 


\section{Abstract}

Acoustic properties of residential building are often neglected by designers, developers, contractors, and even home buyers. Noises from both the internal and external environments affect occupants' daily lives. This motivates the current study which aims to identify all types of audible noises in Malaysian residential buildings and to determine the physical and psychological impact of noise loudness and annoyance on occupants in various types of residential buildings. A questionnaire was conducted covering 19 types of noises in residential buildings with participants assessing the loudness and annoyance level. There were 171 valid forms collected from around Malaysia for analysis from one thousand posted forms, responding rate of $17.1 \%$. Traffic noises were deemed as the most undesired type of noise, followed by the noises from neighbors and animals. More interestingly, the annoyance experienced in relation to noise from traffic and neighbors were intercorrelated. While many animal noises such as birds chirping, rooster calls, and insect noise cause little irritation to occupants, dogs barking are significantly more annoying to the occupants. Job stress and occupants' sensitivity to noise are highly correlated with many types of noises. Generally, the influences of human-related factors are more significant relative to the housing-related factors on the perceived noise loudness and annoyance.

Keywords: building acoustic performance, residential building service, noise annoyance, noise loudness,

\section{PRACTICAL APPLICATION}

The result of this study could directly assist building developers and architects to enhance the acoustic (sound) properties of residential buildings. This study will guide potential property buyers how to look into the acoustic performance of the building that they are going to purchase and to stay 
This is a copy of the "Post-print" (i.e., the authors" final draft, post-refereeing). Published as:

Wang, C., Si, Y., Abdul-Rahman, H., \& Wood, L. C. (in press). Noise annoyance and loudness: Acoustic performance of residential buildings in tropics. Building Services Engineering Research and Technology.

in. All types of audible noises annoying residents in full range of residential buildings are identified and categorized in this study. The loudness and annoyance of each type of noise to resident occupants were addressed. The physical and psychological impact of noise loudness and annoyance to the occupants in different type of residential buildings are determined, which will improve the fullness of industry standards as well regarding acoustic concern as a trend. 


\subsection{Introduction}

Indoor acoustic condition has a huge impact on people's health, well-being, and general performance. ${ }^{1}$ The problems of residential noises are becoming worse in high density housing areas, rental accommodation areas, and highly urbanized areas. ${ }^{2}$ The higher the time-weighted average noise exposure in decibels, the more serious the risk to people. Persistent environmental noise above 40 dBA will cause annoyance and disturb sleep, while also increasing the risk of a range of issues; e.g., ischemic heart disease, hearing impairment, and mental health problems. ${ }^{3}$ However, acoustic factors are usually accorded little attention during project planning and designing stages. ${ }^{4}$ Designers primarily focus on the functionality and aesthetics but ignore the acoustic comfort afforded by a building. The acoustic environment has been neglected during the education of building engineers and architects relative to the thermal and lighting aspects addressed in education programs. ${ }^{5}$ Building noise control may be expensive due to the lack of research on noise source, annoyance, loudness, and the resulting physical and psychological impacts on inhabitants. Architects and designers should not overlook these influences as they can jeopardize the acoustical environment. ${ }^{6}$

Many occupants are not satisfied with the indoor acoustic environment, despite the development of acoustic standards. ${ }^{7}$ The response of occupants to noise is unquantifiable and depends on the strength of the emitted signal and the background noise in the receiving situation; a way has to be found to transfer this information and communicate about the issue without forcing people to understand the nature of decibels or the meaning of noise insulation indices. ${ }^{8,9}$ Though acoustic comfort was listed in the Internal Environment Quality (IEQ) criteria in Green Building Index, very few studies have been conducted on building noise in Malaysia, especially the impact of noise on residential buildings' occupants and how they perceive the loudness and how annoying it is. ${ }^{10}$ Therefore, the aim of this study is to identify all types of audible noises in residential buildings and to determine the physical 
This is a copy of the "Post-print" (i.e., the authors' final draft, post-refereeing). Published as:

Wang, C., Si, Y., Abdul-Rahman, H., \& Wood, L. C. (in press). Noise annoyance and loudness: Acoustic performance of residential buildings in tropics. Building Services Engineering Research and Technology.

and psychological impact of noise loudness and level of annoyance to occupants in various types of residential buildings.

This article proceeds by first reviewing literature on acoustic comfort and noise, examining different factors and differences between the types of dwelling. These factors were used to inform the questionnaire and we next explain the methodology used to address the research aim. After this, we present our findings and discuss these in relation to extant literature.

\subsection{Acoustic Comfort and Noise}

Acoustic issues relate to the perception of noise. Humans can hear frequencies of approximately $20 \mathrm{~Hz}$ to $20,000 \mathrm{~Hz} .{ }^{11}$ Noise is subjective and one man's music might be another man's noise. ${ }^{5}$ Noise is one of the most common environmental problem to people. In Sweden, almost 25\% people consider themselves exposed to noise. ${ }^{12}$ Noise annoys because it masks other sounds, it makes intellectual activities difficult, disturbs one's attention and concentration, leads to physiological arousal, and triggers negative affective/emotional reactions.

\subsection{Acoustic Comfort}

Acoustic comfort is a state of contentment with acoustic conditions. Acoustic comfort is a complex aspect to evaluate. ${ }^{6}$ In fact, the presence of a pleasant sound could considerably improve acoustic comfort, even if its volume is quite high. Perceived intensity therefore needs to be combined with subjective acoustic satisfaction to provide a comprehensive picture of acoustic comfort. ${ }^{9}$ Most previous studies have shown the physical and psychological status of building users affected by noise. $^{1}$ 
The seminal study on acoustic comfort, by Commins and Meier (1978), identified that acoustic comfort is affected by factors such as: a) human sources (e.g., voice, steps, movements, radio, or television); b) individual equipment (e.g., apartment heaters and washing machines); c) domestic equipment; d) collective equipment (e.g., heaters, lifts, transformers, or air conditioners); and e) outdoor noise (e.g., automobiles, buses, railway, aircraft noise, or industrial noises). ${ }^{11}$ Besides that, acoustical comfort also depends on building characteristics. The transmission of sound waves through walls, windows, ducts, shafts, and openings, and the transmission of vibrations through the structure will determine the sound pressure level, resulting in a room filled with sounds from both the indoor and outdoor sources. ${ }^{11}$ Noise could influence occupants' health and productivity. It was reported to create physical health problems such as cardiac problems, sickness related absenteeism and self-reported fatigue. Poor acoustic environment also causes harm to occupants' psychological health. Noisy and uncomfortable spaces create disturbances and breaks occupants' concentration, resulting in stressed occupants. ${ }^{13}$

\subsection{Acoustic Properties of Residential Buildings}

Acoustic properties of residential buildings are correlated with many factors making them difficult to measure. ${ }^{14}$ Furthermore, occupants' evaluation of noises is subjective; even the same type of noise leads to different levels of acoustic comfort for different people. The relationship of human-related factors and how they influence occupants' noise annoyance have been increasingly studied in recent years. Sound is characterized by both sound pressure and sound frequency. ${ }^{15}$ Numerous studies have focused on two main sets of factors influencing noise annoyance: a) sound-related factors, the physical characteristics of sound (e.g., type of noise, noise level, duration of exposure, frequency spectrum, the time of day when exposure occurs, and previous experience with the noise source); and 
This is a copy of the "Post-print" (i.e., the authors' final draft, post-refereeing). Published as:

Wang, C., Si, Y., Abdul-Rahman, H., \& Wood, L. C. (in press). Noise annoyance and loudness: Acoustic performance of residential buildings in tropics. Building Services Engineering Research and Technology.

b) human-related factors (e.g., physiological, psychological) and social factors that affect the perception of noise and impair activities (e.g., communication, concentration, sleep, and recreation or rest). ${ }^{16}$ From a public health perspective, these factors should not be observed separately and they might not play equally important roles. ${ }^{16}$

\subsubsection{Housing-related Factors}

In a residential building, human beings are affected by structure-borne acoustical phenomena either in the form of airborne sound or structure-borne sound. ${ }^{11}$ Sound can transmit into rooms through airborne sound or through building structure vibrations. There are a variety of noise sources within residential buildings. In particular, multi-story buildings or neighboring apartment units which share walls, ceilings and floor structures provide structure-borne sound paths for the propagation of floor impact, airborne, and drainage noises. The propagation of these residential noise sources has been identified as a major cause of annoyance for apartment residents. ${ }^{20}$ Sound insulation components such as floors, walls, and windows are important factors in selecting a residential building. Even a small opening on a partition wall could greatly increase the propagation of noise. Furthermore, the material used to construct the building components will affect the reverberation time of sound. ${ }^{20}$ Orientation of windows, type of sound isolation, and floor level could affect the perception of noise. Floor level is significantly and inversely correlated with the extent of noise annoyance. ${ }^{16}$ Furthermore, there is an association between traffic noise annoyance and the availability of relative quietness at the least exposed side of dwelling. ${ }^{21}$

Housing stock is usually categorized as: a) Detached single unit housing, b) Semi-detached dwelling, c) Attached single unit housing, d) Attached multi-unit housing, and e) Movable dwelling. Detached single unit housing units are not attached to other housing. Semi-detached dwellings are attached to 
This is a copy of the "Post-print" (i.e., the authors' final draft, post-refereeing). Published as:

Wang, C., Si, Y., Abdul-Rahman, H., \& Wood, L. C. (in press). Noise annoyance and loudness: Acoustic performance of residential buildings in tropics. Building Services Engineering Research and Technology.

another house on one side. Attached single unit housing is attached to other houses on both sides, while attached multi-unit housing is attached to other accommodation on the left, right, top, and bottom sides. The type of residential building will influence the properties of audible noise. As noises are transmitted through a medium, either by air (air borne noise) or by structure (structure borne) into a building, ${ }^{17}$ those buildings attached to other buildings will suffer in structure borne noise from each other.

\subsubsection{Human-related Factors}

Human-related factors significantly influence the noise annoyance. ${ }^{9}$ Perceptions of the same indoor environment will vary among different building users. Gender, education level, age, and type of work are correlated with the perceptions of indoor acoustic quality. ${ }^{1}$ Many social factors may affect annoyance reactions and personal attitudes to noise and its sources may influence noise annoyance. ${ }^{23}$ General negative attitudes toward the acoustic environment were shown to increase noise annoyance. $^{24}$ The stress level of occupants is closely related to acoustic satisfaction; occupants exposed to stressful situations are more likely to react to noise stimuli with a higher level of noise annoyance. ${ }^{16}$ Therefore, their working environment also influences acoustic satisfaction. ${ }^{9}$

\subsection{Annoyance of Noise}

The loudness of noise is objectively measurable with appropriate equipment, but the annoyance to occupants cannot be measured directly. ${ }^{17}$ Noise exposure may be extremely disturbing when the noise masks auditory information required for the ongoing activity. The effect of a noise exposure may also be influenced by behavioral responses related to predictability, controllability, informational content, attitudes, and individual differences. ${ }^{12}$ 
The acceptable level of background noise inside a room is established when the noise from sources outside the room are not discernible when normal activities are in operation within the room. ${ }^{18}$ There is a significant effect of background noise level $(\mathrm{p}<0.01)$ on annoyance. ${ }^{19}$ The relationship between loudness and annoyance of noises are widely studied; basically, annoyance as well as negative effects on performance will increase with increasing sound level, tonal character of the noise, and variability of the exposure. ${ }^{12}$ Annoyance also depends upon the type of noise. ${ }^{20}$

The most significant noise sources include road traffic noise, construction noise, neighborhood noise, elevator noise, and industrial noises. ${ }^{16}$ Lee et al. (2010) tried to conduct tests on indoor multiple noise sources in residential buildings, but the difficulties in providing an accurate prediction for each source were caused by the effect of interaction among noise sources along with the non-acoustical aspects; e.g., occupants' sensitivity to noise. ${ }^{20}$

The frequently reported annoying floor-impact noise is caused by musical instrument and children jumping, playing, and running. Flushing toilets and bathtubs are the most annoying drainage noises. Floor impact noise was found to be the most annoying source in residential buildings followed by airborne noise, traffic noise, and drainage noise. ${ }^{20}$ Zannin and Bunn (2014) added animal noise to this list. ${ }^{15}$ For construction noise, the type of construction equipment and the number of workers are significant criteria for the noise level in the vicinity of a construction site. ${ }^{2}$ Decisive factors, however, include the technical skills of the workers, which were always underestimated. ${ }^{17}$

While previous studies have generally examined acoustic comfort by treating housing stock as homogenous, the aim of this study is to examine the physical and psychological impact of noise volume and annoyance in various types of residential buildings. 


\subsection{Research Method and Procedures}

To address the research objective of understanding and being able to compare loudness and annoyance levels, a quantitative approach was required. As the focus is on the perception and level of annoyance experienced in relation to noise, a questionnaire approach was used to capture the perceptions of noise as Lee et al. (2010) demonstrated that objective measurements of noise are made difficult due to non-acoustic properties such as residents' sensitivity to noise. ${ }^{20}$ Based on existing research results outlined in $\S 2$, a series of questions were developed that would be useful in understanding the residents' opinions and perspectives on the volumes, and annoyance associated with different noises. A pilot questionnaire was provided to nearby residents and experts for feedback. Based on the feedback, some questions were altered to make them more easily understood. The final questionnaire covered 19 types of noises in residential buildings with assessment of loudness and annoyance levels. The targeted population was residential building occupants in Malaysia aged from 20 to 26, including both locals and foreigners. The restriction on age was set to ensure the high construct validity because the hearing system of human is very subjective to the age. People older than 26 years face gradual degeneration of hearing acuity, especially for high frequency noises. On the other hand, people below 20 years old are considered to still be in puberty and the resulting hormone instability might slightly affect the hearing system. By limiting the sample to ages 20 to 26 , the research controls for these factors. Apart from that, where a respondent reported a hearing disability, these data were discarded to avoid bias in the analysis.

To reach this target population, it was decided that a mail-based questionnaire would be distributed. This enabled us to collect data from all over Malaysia, providing us with the opportunity to sample residents in a range of urban, suburban, and rural settings. There were 171 valid forms collected for 
This is a copy of the "Post-print" (i.e., the authors' final draft, post-refereeing). Published as:

Wang, C., Si, Y., Abdul-Rahman, H., \& Wood, L. C. (in press). Noise annoyance and loudness: Acoustic performance of residential buildings in tropics. Building Services Engineering Research and Technology.

analysis among 1,000 distributed forms, forming a responding rate at $17.1 \%$ which provided a suitable sample size and is considered a reasonable response rate for questionnaire research. Respondents consist of 96 females (56\%) and 75 males (44\%). Table 1 lists the distribution of states for respondents' house locations from 14 states in Malaysia. Most of the respondents are from Kuala Lumpur (35.1\%), followed by Selangor (13.5\%) and Perak (10.5\%). Johor, Pulau Penang, Pahang, Melaka, Negeri Sembilan, Sarawak, Terengganu, Kedah, Kelantan, and Sabah each accounted for less than $10 \%$ of the respondents.

Table 1: Distribution of states for respondents' house locations

\begin{tabular}{|c|c|c|}
\hline States & Number of respondents & Percentage (\%) \\
\hline Kuala Lumpur & 60 & $35.1 \%$ \\
\hline Selangor & 23 & $13.5 \%$ \\
\hline Perak & 18 & $10.5 \%$ \\
\hline Johor & 16 & $9.4 \%$ \\
\hline Penang & 13 & $7.6 \%$ \\
\hline Pahang & 11 & $6.4 \%$ \\
\hline Melaka & 7 & $4.1 \%$ \\
\hline Negeri Sembilan & 6 & $3.5 \%$ \\
\hline Sarawak & 4 & $2.3 \%$ \\
\hline Terengganu & 4 & $2.3 \%$ \\
\hline Kedah & 3 & $1.8 \%$ \\
\hline Kelantan & 3 & $1.8 \%$ \\
\hline Sabah & 3 & $1.8 \%$ \\
\hline Total & $\mathbf{1 7 1}$ & $\mathbf{1 0 0 \%}$ \\
\hline
\end{tabular}

The types of housing included in this study are detached houses, semi-detached houses, terrace house, and apartment/condominium. Particularly, terrace houses and semi-detached houses are the most popular housing types in Malaysia, because these landed properties are still affordable to most house buyers. Whether or not the house faces a highway was included as one question to capture the impact of traffic noise. Questions regarding the cost range and location of houses were used in determining the variance among different noise types. The questionnaire covers the job stress and occupants' sensitivity to noise to address psychological factors. The types of noise included in this study were permanent noises in residential buildings; thus, those temporary noises (e.g., construction noise and airplane noise) were excluded to ensure internal validity as these temporary noises did not impact on every respondent. A four point scale Likert-type scale system was applied to avoid respondents' 
This is a copy of the "Post-print" (i.e., the authors' final draft, post-refereeing). Published as:

Wang, C., Si, Y., Abdul-Rahman, H., \& Wood, L. C. (in press). Noise annoyance and loudness: Acoustic performance of residential buildings in tropics. Building Services Engineering Research and Technology.

tendencies to select a mid-point or neutral option. The 19 types of noises were grouped into four categories (Table 2).

Table 2: Types of noise in 4 categories

\begin{tabular}{|l|l|l|l|}
\hline Traffic Noise & Neighbor noise & Self-house noise & Animal noise \\
\hline Motorcycle & Talking & Cooking & Dog \\
Car and van & Chouting & Children playing & ooster \\
Bus and lorry & Children playing & Baby crying & Bird \\
& Baby crying & TV or loud music & Insect \\
& Coughing & Door banging & \\
& TV or loud music & & \\
& Door banging & & \\
\hline
\end{tabular}

Descriptive analysis of loudness and annoyance levels was presented using bar charts to visualize and to compare means. A correlation test was used to test the relationship between independent variables (e.g., "job stress level” and "occupants' sensitivity on noise”) with dependent variables (e.g., "loudness of noise" and "annoyance of noise"). A one-way ANOVA with post-hoc tests was used to evaluate the relationship between dependent variables and independent categorical variables; e.g., “working environment", "housing type", and "house location”. Further, the Spearman's Rank Order Correlation test was used to assess the strength of the relationship between "loudness of noise" and "annoyance of noise". The Partial Least Square algorithm was used in Smart PLS 2.0 to identify the path coefficients within variables and indicators. Table 3 summarizes the housing-related and human-related factors.

Table 3: Summary of housing-related and human-related factors

\begin{tabular}{|c|c|c|c|c|c|}
\hline Housing-related Factors & $\mathrm{N}$ & $\%$ & Human-related Factors & $\mathrm{N}$ & $\%$ \\
\hline Housing type & & & Working Environment & & \\
\hline Detached house & 25 & $14.62 \%$ & Quiet Indoor & 128 & $74.85 \%$ \\
\hline Semi-detached house & 30 & $17.54 \%$ & Noisy indoor & 14 & $8.19 \%$ \\
\hline Terrace & 88 & $51.46 \%$ & Quiet outdoor & 12 & $7.02 \%$ \\
\hline Condominium/ Apartment & 28 & $16.37 \%$ & Noisy outdoor & 17 & $9.94 \%$ \\
\hline Location of house & & & Job Stress Level & & \\
\hline Urban & 79 & $46.20 \%$ & Minimum stress & 14 & $8.19 \%$ \\
\hline Suburban & 53 & $30.99 \%$ & Slightly stress & 62 & $36.26 \%$ \\
\hline \multirow[t]{2}{*}{ Rural } & 39 & $22.81 \%$ & Quite stress & 79 & $46.20 \%$ \\
\hline & & & Very stress & 16 & $9.36 \%$ \\
\hline \multicolumn{6}{|l|}{ Facing Highway } \\
\hline Yes & 33 & $19.30 \%$ & Feeling When Distracted & & \\
\hline \multirow[t]{2}{*}{ No } & 138 & $80.70 \%$ & Not feeling uncomfortable & 7 & $4.09 \%$ \\
\hline & & & Slightly uncomfortable & 30 & $17.54 \%$ \\
\hline Occupants' sensitivity on noise & & & Quite uncomfortable & 49 & $28.65 \%$ \\
\hline Not sensitive & 6 & $3.51 \%$ & Very uncomfortable & 85 & $49.71 \%$ \\
\hline Slightly sensitive & 39 & $22.81 \%$ & & & \\
\hline Quite sensitive & 79 & $46.20 \%$ & Willingness to Pay & & \\
\hline Very sensitive & 47 & $27.49 \%$ & Yes & 146 & $85.38 \%$ \\
\hline & & & No & 25 & $14.62 \%$ \\
\hline
\end{tabular}

\subsection{Descriptive Analysis}




\subsection{Housing-related Factors}

More than half of the respondents (51.46\%) reside in terrace housing, while the respective percentages of residents staying in other three types of housing are similar, ranging from $14.62 \%$ to 17.54\%. Terrace housing is usually cheaper than detached or semi-detached housing, but more expensive than condominium or apartment units. Most respondents live in urban areas (46.20\%), $30.99 \%$ live in suburban areas, followed by $22.81 \%$ living rurally. Residential houses in Malaysia were usually developed near highways or main roads to ease transportation; in the questionnaire $19.30 \%$ of respondents' residences face the highway.

\subsection{Human-related Factors}

There were about one quarter $(27.49 \%)$ of the respondents who reported being very sensitive to noise, followed by $69.01 \%$ who are slightly sensitive to noise, with only $3.51 \%$ reporting that they were not sensitive at all. The working environment for most respondents $(71 \%)$ was indoor and quiet, but $82.46 \%$ of them reported work stress, and all of them felt uncomfortable when distracted by noise at home. A question was asked in the questionnaire whether respondents were willing to buy a new house with better acoustic properties but which would be $25 \%$ more expensive. The purpose of this question was to test the perceived importance of acoustic comfort. Most respondents (85\%) indicated a willingness to pay the additional cost for better sound quality. In current practice, the acoustic properties are not considered by most developers when designing and constructing residential housing. Since most of the respondents are willing to pay more for better acoustic properties, new developments with carefully designed and managed acoustic properties might become increasingly attractive to potential buyers. 


\subsection{Noise Distracting Level}

The 19 types of noise were in four categories: traffic noises, neighbor noises, own house noises, and animal noises. Around half respondents (49.11\%) perceived traffic noises as most distracting, followed by neighbor noises, own house noises, and animal noises (with similar percentages). The mean loudness and annoyance level for each noise was broken down in Figure 1, showing a generally similar curve between loudness and annoyance. The perceived annoyance of noises in the occupant's own house is less than the annoyance of noises from the neighboring houses. For animal noise, the noise from dogs barking is much louder and more annoying compared to other animals.

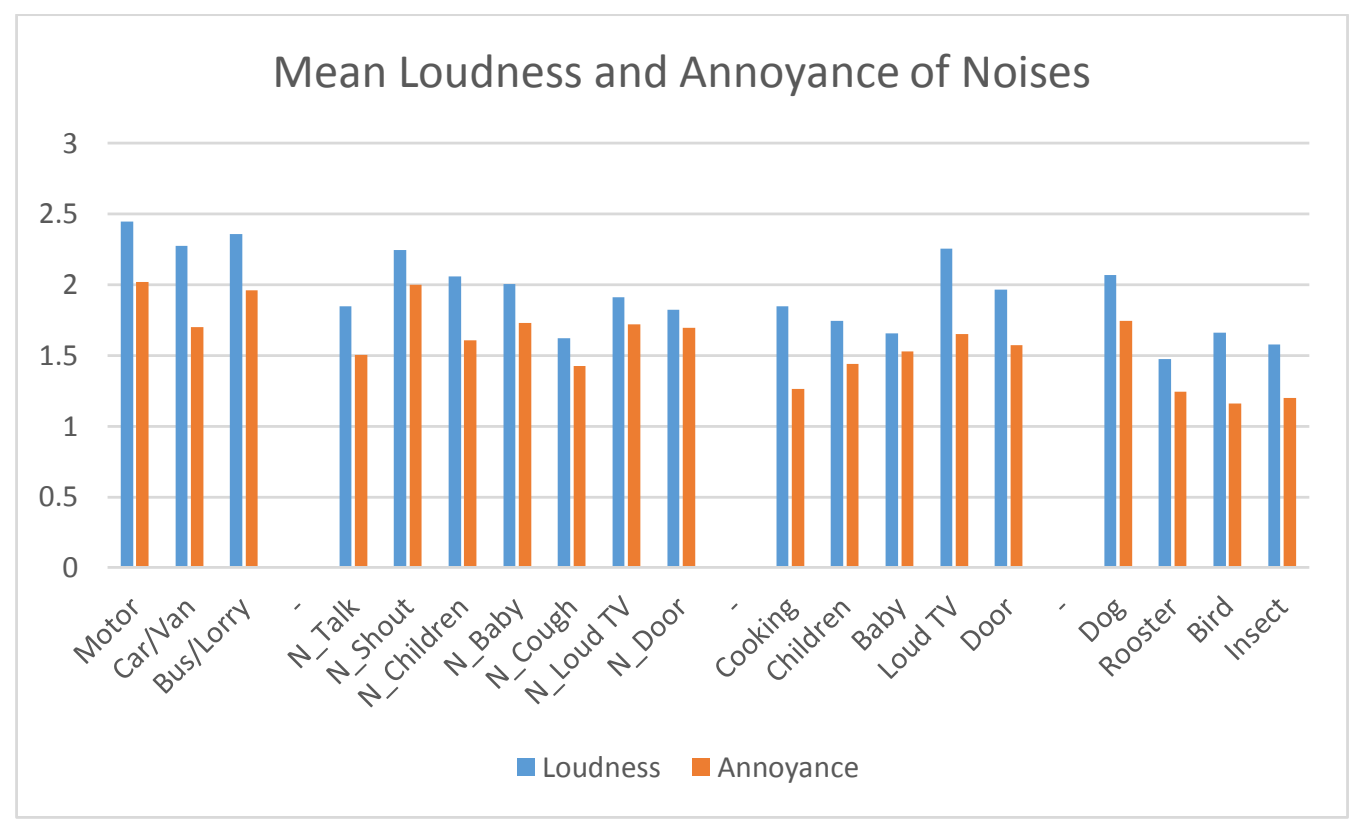

Figure 1: Loudness and Annoyance of Noises

\subsection{Annoyance Level and Housing Type}

The annoyance levels of different types of noise were analyzed with housing-related factors including: housing type, house location, and whether it is facing the highway. According to Figure 2, 
This is a copy of the "Post-print" (i.e., the authors' final draft, post-refereeing). Published as:

Wang, C., Si, Y., Abdul-Rahman, H., \& Wood, L. C. (in press). Noise annoyance and loudness: Acoustic performance of residential buildings in tropics. Building Services Engineering Research and Technology.

semi-detached houses encounter the loudest traffic noise, while terrace houses and apartments do not suffer that much from traffic noises. In addition, the annoyance of traffic noise for semi-detached housing is also much higher than that of the other three housing types. Among the three kinds of traffic noises, buses and lorry have the highest loudness and annoyance compared to cars and vans. It is also important to note that low frequency noise such as traffic noise is difficult to insulate against in terms of either airborne or structural borne noise.

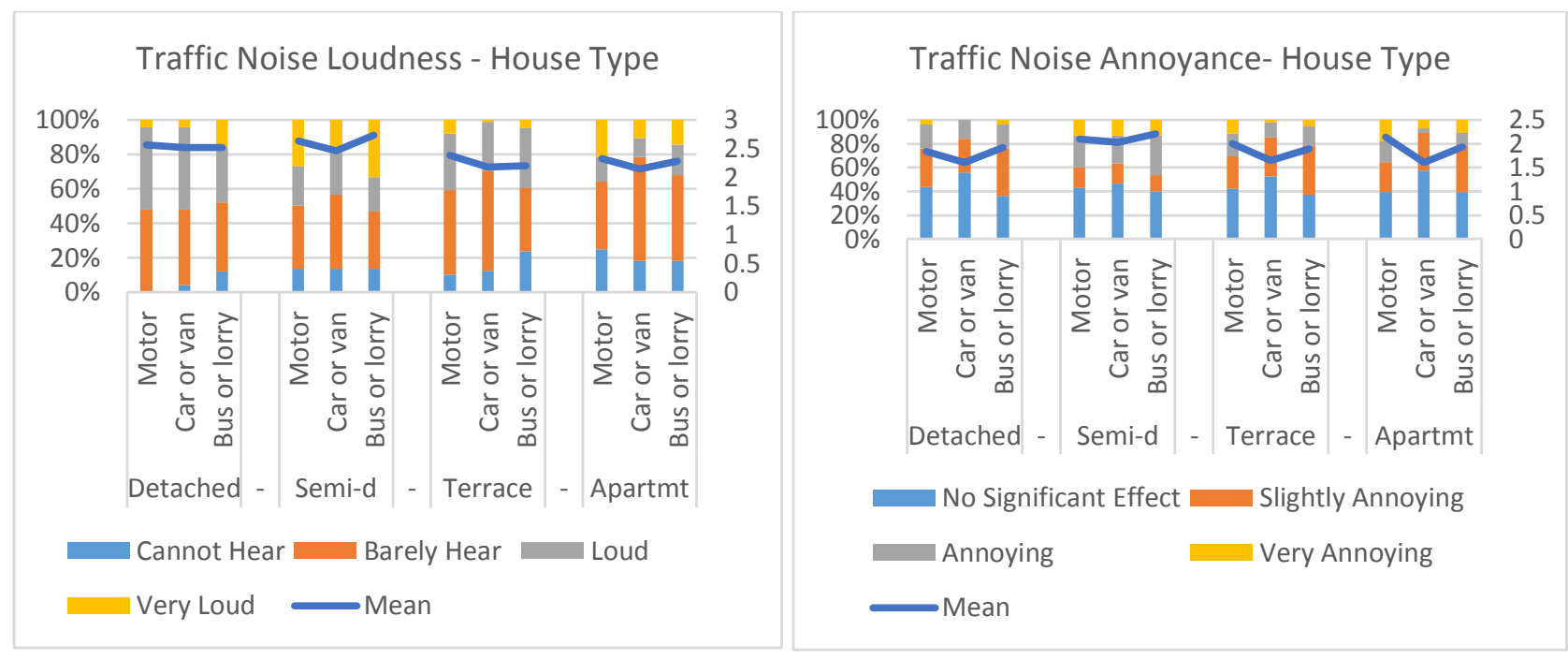

Figure 2: Traffic Noise and Housing Type

The loudness and annoyance of neighbor noises in detached houses is lower than that in other housing types (Figure 3). The noise condition in apartments or condominiums is the worst. Particularly, the noise of the neighbor's door banging is perceived as much louder in apartments than in other types of housing. 
This is a copy of the "Post-print" (i.e., the authors' final draft, post-refereeing). Published as:

Wang, C., Si, Y., Abdul-Rahman, H., \& Wood, L. C. (in press). Noise annoyance and loudness: Acoustic performance of residential buildings in tropics. Building Services Engineering Research and Technology.

Neighbor Noise Annoyance- House Type

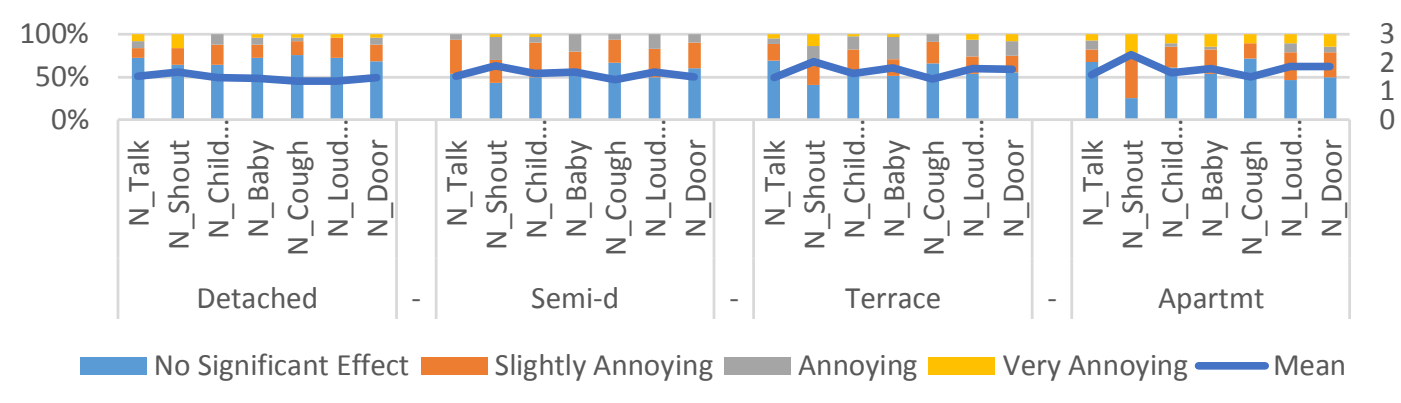

Neighbor Noise Loudness - House Type

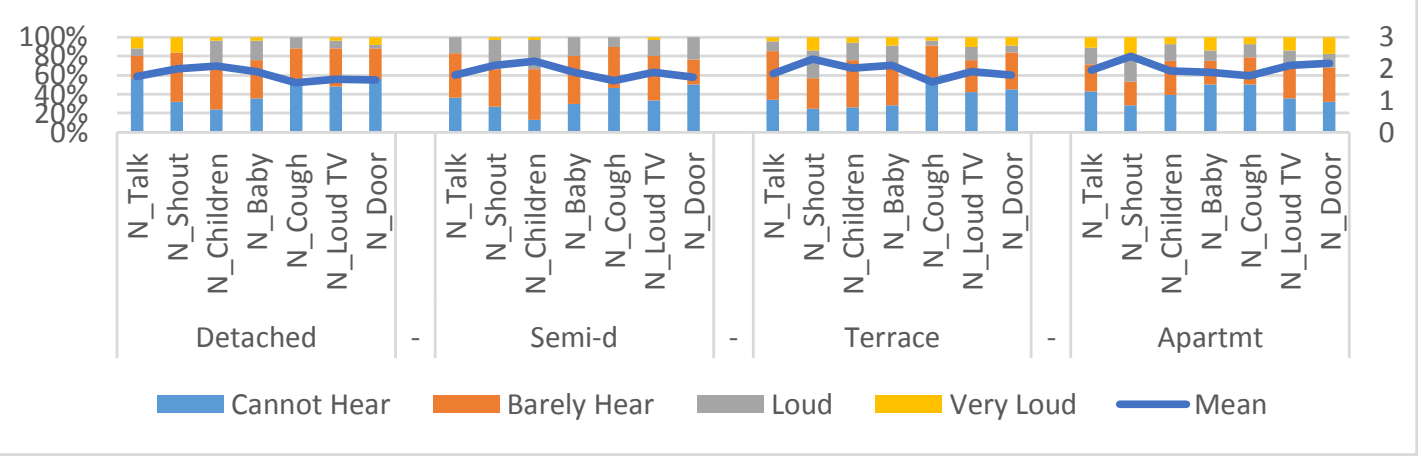

Figure 3: Neighbor Noise and Housing Type

Figure 4 shows that occupants of semi-detached housing report the lowest loudness and annoyance levels in relation to animal noises. Terrace housing has exceptionally high loudness and annoyance levels relating to dog barks, while the noise of roosters, birds, and insects are similar between semidetached houses and apartments. Among the four types of animal noises, dog barking is the most annoying noise. Although the birds' chirp is often louder and more pervasive than roosters and insects in all types of housing, it is the least annoying to occupants; this may be because the timbre is more pleasant than other types of animal noises. 
This is a copy of the "Post-print" (i.e., the authors' final draft, post-refereeing). Published as:

Wang, C., Si, Y., Abdul-Rahman, H., \& Wood, L. C. (in press). Noise annoyance and loudness: Acoustic performance of residential buildings in tropics. Building Services Engineering Research and Technology.

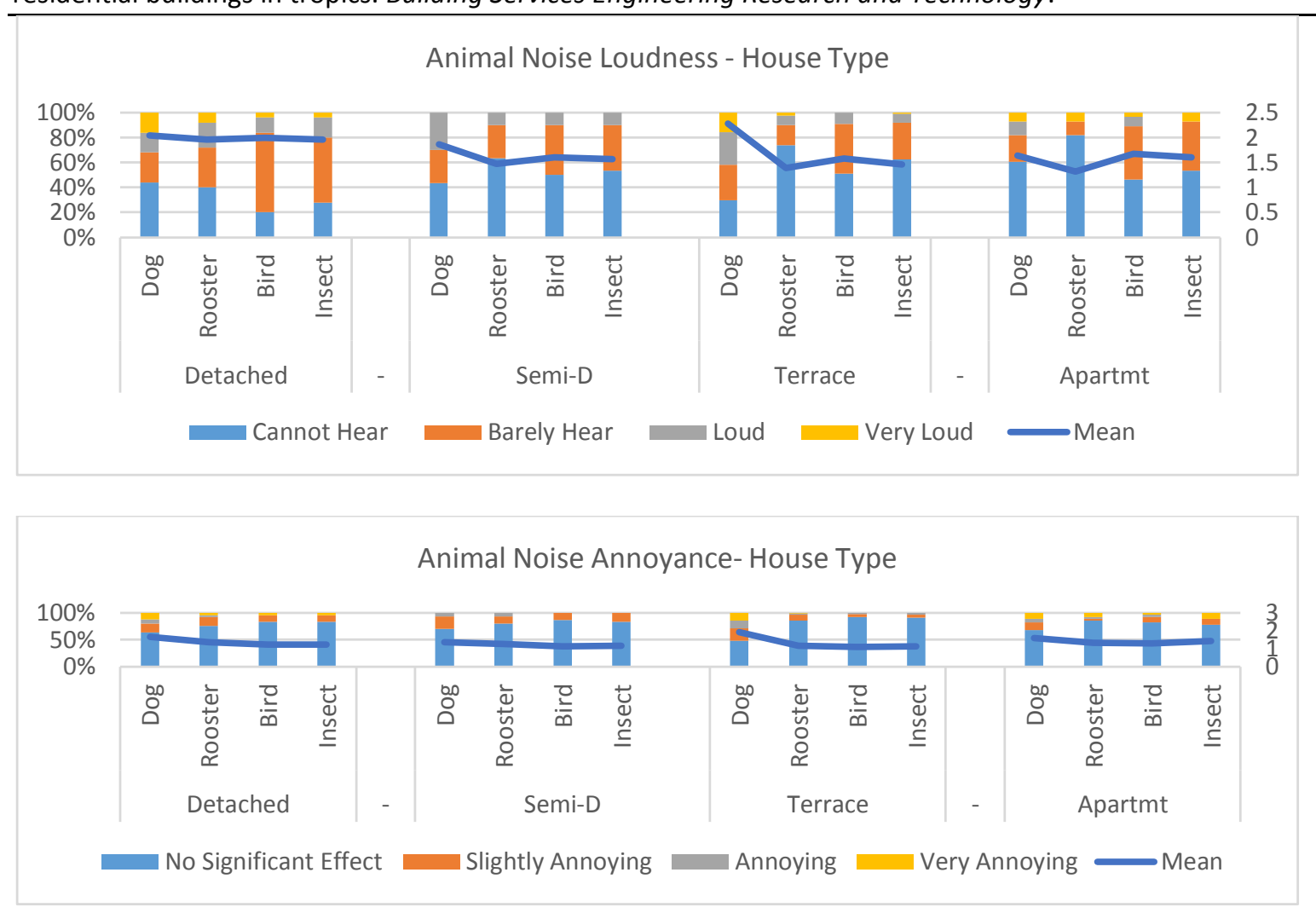

Figure 4: Animal Noises and Housing type

\subsection{Location and Orientation of House}

Urban houses face lower motorcycle noise but greater bus or lorry noise compared to suburban and rural houses. The suburban house has higher noise for every kind of traffic noise compared to the rural house. According to Figure 5, rural housing faces the loudest neighbor shouting noises compared to urban and suburban housing. The noises from TV and music in suburban houses are significantly louder than that in urban and rural houses. The annoyance graph shows that urban house and rural house have similar annoyance properties. Banging doors causes the highest annoyance to suburban occupants. Within this study there were 33 houses facing highways and another 138 not facing highways. The houses facing highways were exposed to louder traffic noises where the loudest and most annoying noise originated from the bus and lorry traffic. Figure 6 ranks the noise 
This is a copy of the "Post-print" (i.e., the authors' final draft, post-refereeing). Published as:

Wang, C., Si, Y., Abdul-Rahman, H., \& Wood, L. C. (in press). Noise annoyance and loudness: Acoustic performance of residential buildings in tropics. Building Services Engineering Research and Technology.

annoyance in descending order, which shows that the occupants living in the houses facing highway perceive both higher loudness and higher annoyance.
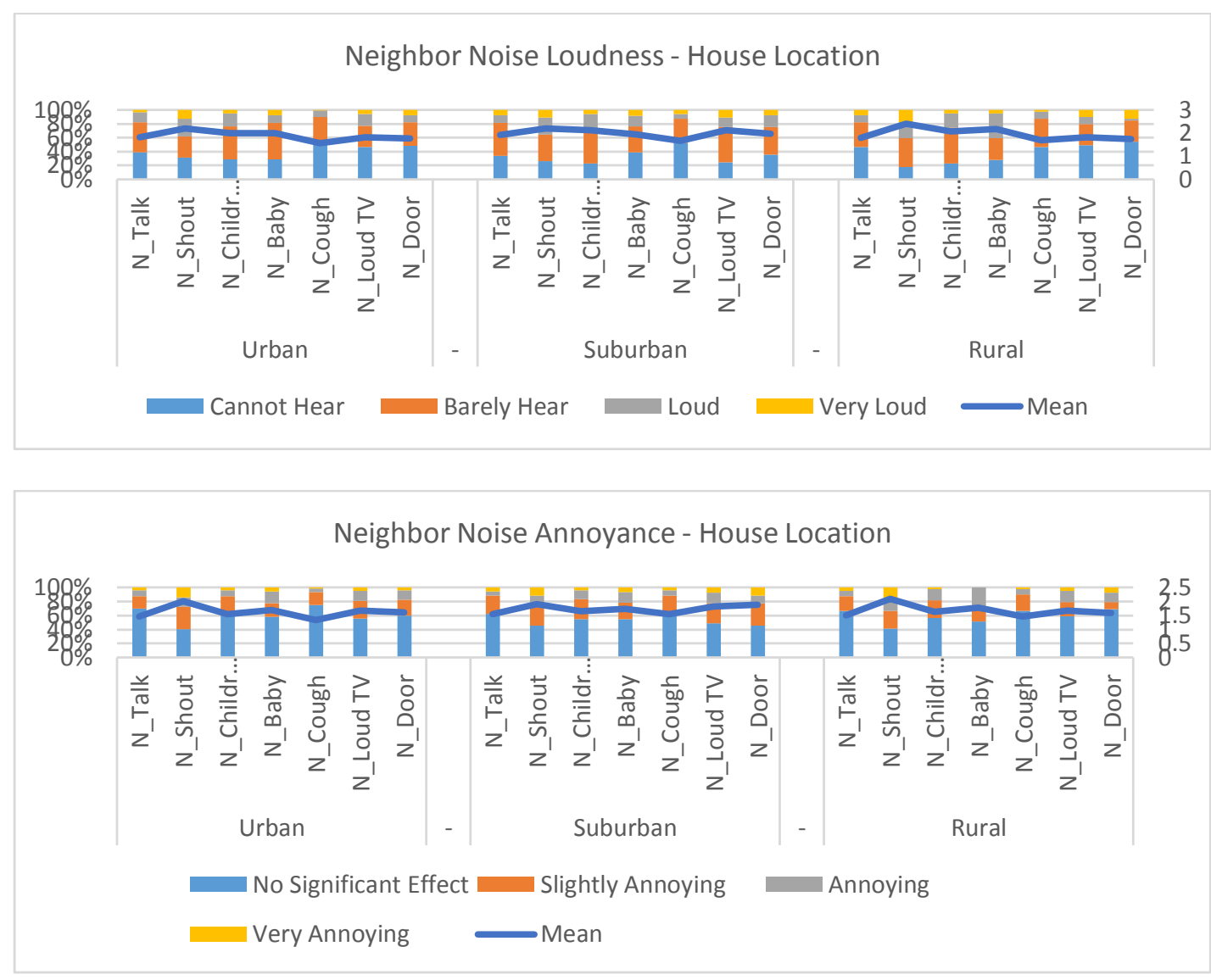

Figure 5: Neighbor Noises and House Location 
This is a copy of the "Post-print" (i.e., the authors' final draft, post-refereeing). Published as:

Wang, C., Si, Y., Abdul-Rahman, H., \& Wood, L. C. (in press). Noise annoyance and loudness: Acoustic performance of residential buildings in tropics. Building Services Engineering Research and Technology.

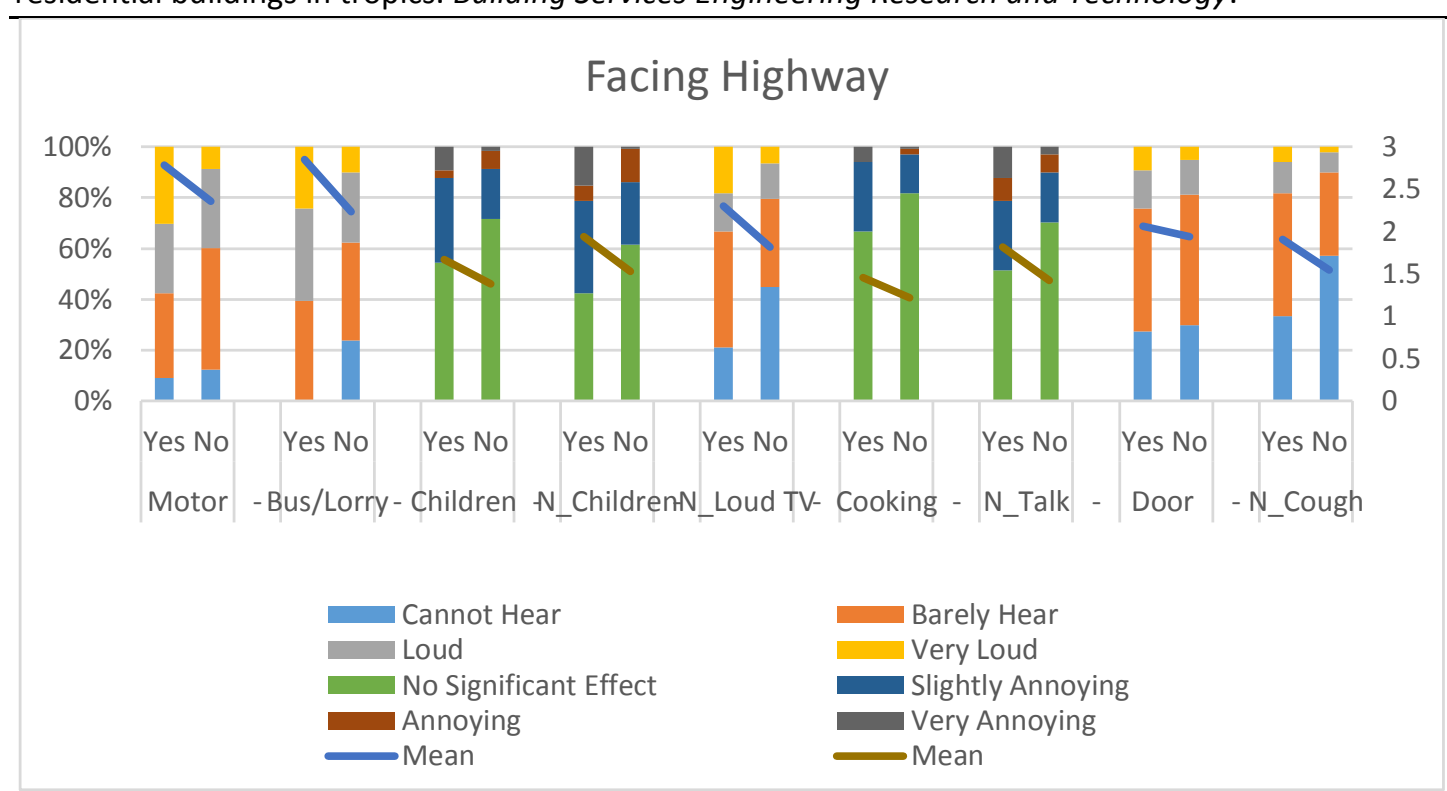

Figure 6: Noises affected by facing highway

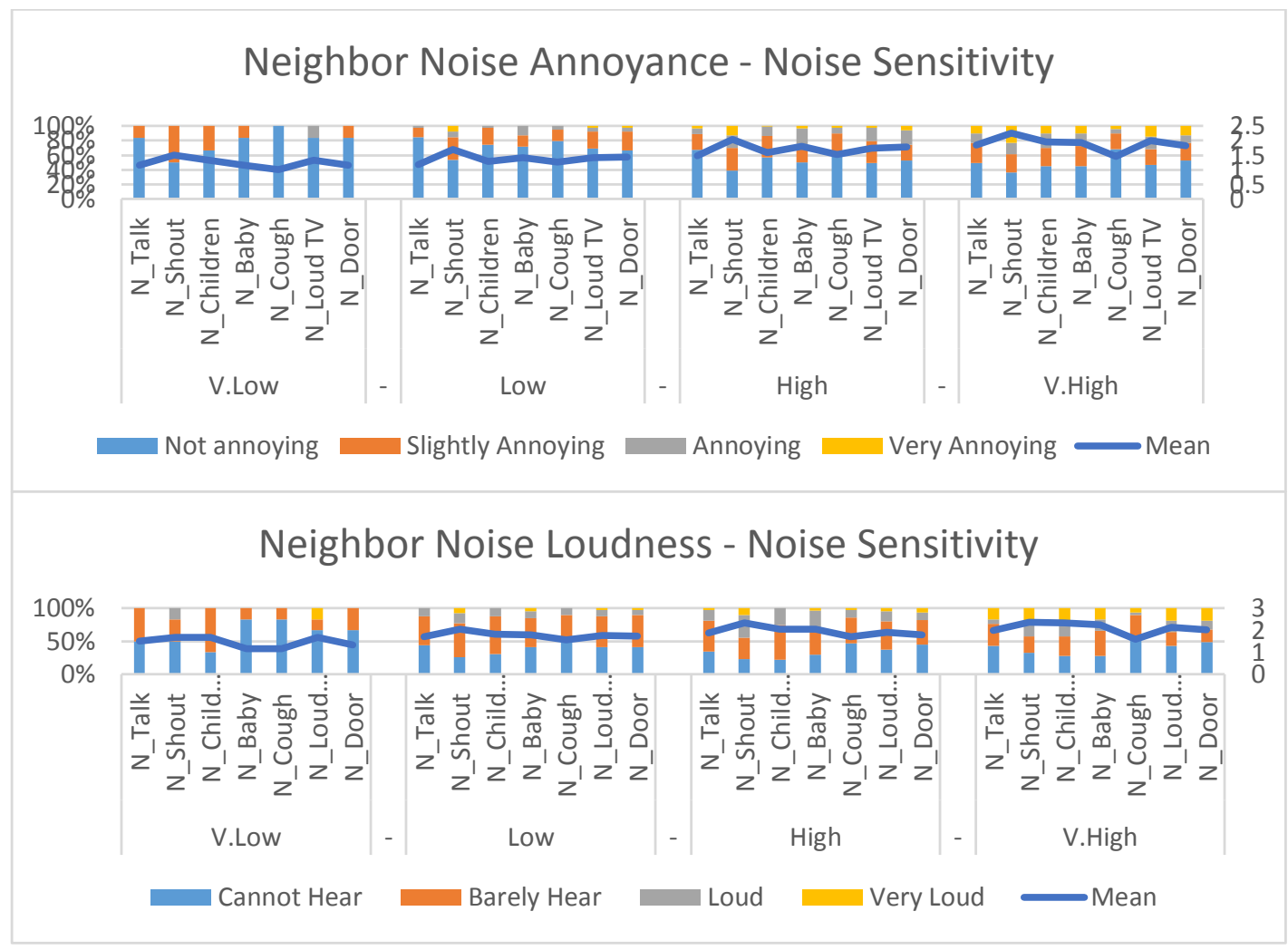

Figure 7: Neighbor Noises and Occupants' sensitivity on noise

\subsection{Occupants' Sensitivity to Noise}


The curves of sensitivity for traffic and animal noises are quite similar to that of the sensitivity to overall noises, thus the graphs are not presented here. For the neighbors' noises, according to Figure 7, the cry of babies was perceived as most annoying and amongst the loudest noise when occupants are sensitive towards noise. In contrast, the perception of coughing is not influenced by sensitivity to noise.

\subsection{Inferential Analysis among Housing and Human Factors to Noise}

To determine the physical and psychological impact of noises on residents, we examined how the different types of noise (i.e., treating the housing-related factors and human-related factors as independent variables) relate to the loudness and annoyance of noise (i.e., treating these as dependent variables).

\subsection{Correlation between Human-related Factors and Noise}

Correlation analysis was conducted between continuous variables "Job stress level”, "Occupants' sensitivity on noise", "Distracted by noise", and "Facing highway" and dependent continuous variables "Loudness of noise" and "Annoyance of noise". According to Table 4, job stress does not affect occupants' perception on the annoyance of traffic noise at all. However, it has significant influence on neighbor noise $(\mathrm{p}<0.05)$. Occupants with higher job stress perceive higher annoyance from neighbor noises. The coefficient of determination shows that annoyance of noises from babies $(\mathrm{p}=0.001)$, children $(\mathrm{p}=0.001)$, and doors $(\mathrm{p}=0.027)$ are highly correlated with job stress. The neighbor noises in Table 4 were coded with a prefix "N_". The level of job stress does not affect the occupants' perception on the loudness of noises produced by the occupants' own houses ( $>>0.05)$ 
This is a copy of the "Post-print" (i.e., the authors' final draft, post-refereeing). Published as:

Wang, C., Si, Y., Abdul-Rahman, H., \& Wood, L. C. (in press). Noise annoyance and loudness: Acoustic performance of residential buildings in tropics. Building Services Engineering Research and Technology.

except loud TVs and door closures $(\mathrm{p}<0.05)$. The annoyance of own house noises were more likely

to be affected by the occupants' job stress than the actual loudness of the noise (e.g., in relation to noise from door closures, $\mathrm{p}=0.001$ for annoyance but $\mathrm{p}=0.026$ for loudness). Furthermore, the types of own house noises affected by job stress are similar to that of neighbor noises, which is circumstantial evidence that the impact of job stress on occupants' perception on the annoyance of these types of noises are not coincidental. Interestingly, occupants' perception of all types of animal noises was affected by job stress. The occupants' sensitivity to noise might affect their perceptions toward the loudness and annoyance of all neighbor noises and all traffic noises. However, the perceived annoyance of noises emerging from occupants' own house are not strongly associated with their sensitivity on noise. For example, only noise from cooking, TV, and loud music are weakly associated with sensitivity. The correlation between occupants' sensitivity and animal noises is also not significant $(\mathrm{p}>0.05)$ and only $\operatorname{dog}(\mathrm{p}=0.025)$ and insect noises $(\mathrm{p}=0.005)$ are associated with annoyance. The annoyance experienced more closely relates to the perception of the noise; thus, these noises are loud but not perceived as annoying. In general, traffic noises were regarded as the most distracting noise group, followed by neighbor noise, own house noise, and animal noise. Specifically, the neighbors' shouting is most annoying, followed by motorcycles, bus, lorry, and dogs barking. House cooking and animal noises (except for dogs barking) are not annoying. Table 5 summarizes the relationship between housing- and human-factors and each type of noise. "LOUD" indicates the factor mainly affects the loudness of this type of noise, and "ANNOY" indicates the factor mainly affects the annoyance of this type of noise. If the factor significantly affects both the loudness and the annoyance, it is labeled as "BOTH". The factor of "housing type" can be seen to significantly affect the perception on the loudness of bus and lorry noise, dogs barking, rooster and insect's noises. Generally, housing-related factors have more impact on the perceived loudness while human-related factors impact the perceived annoyance of noises or both. 
This is a copy of the "Post-print" (i.e., the authors' final draft, post-refereeing). Published as:

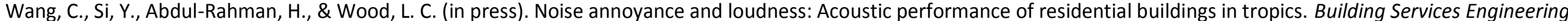
Research and Technology.

Table 4: Correlation between Human-related Factors and Noise

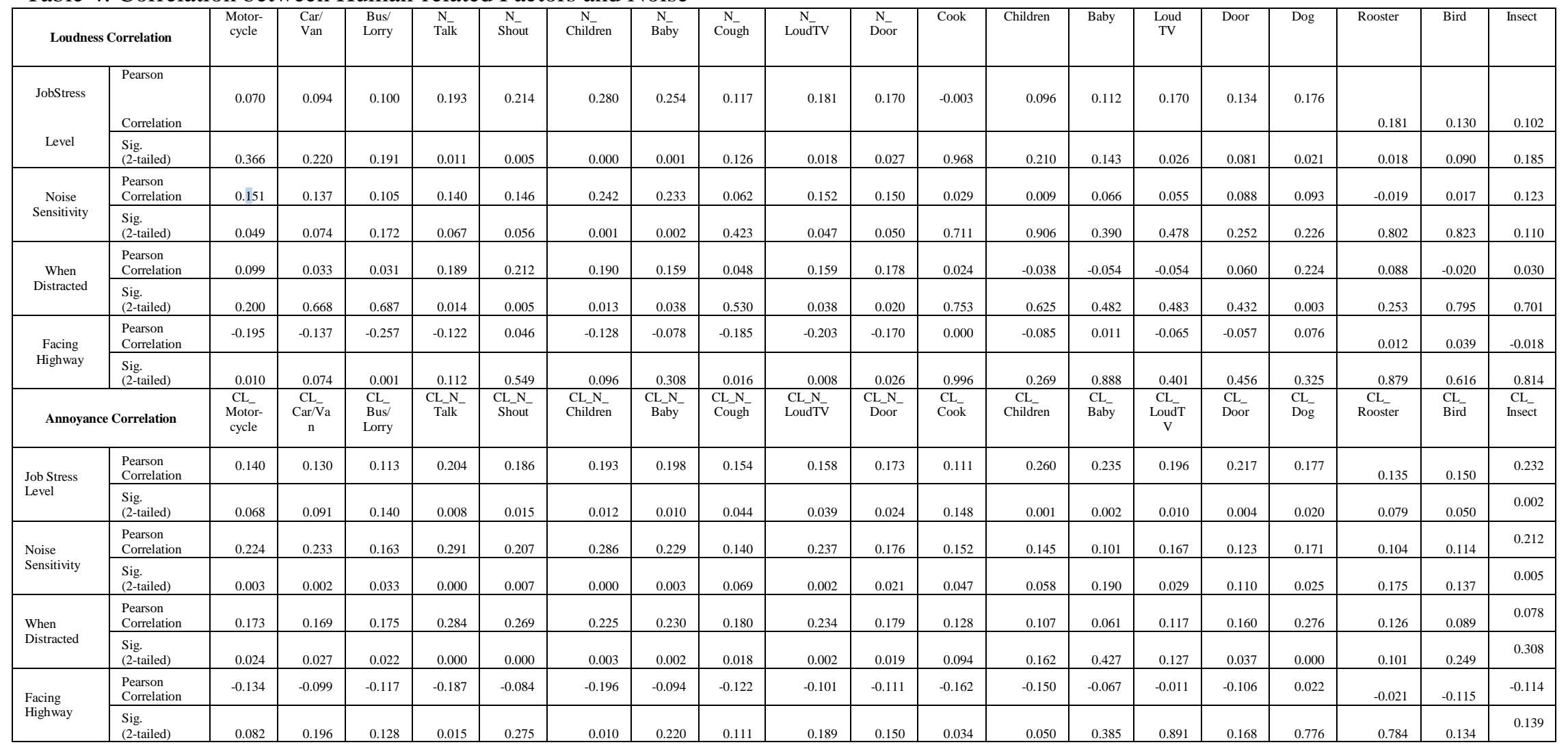


This is a copy of the "Post-print" (i.e., the authors' final draft, post-refereeing). Published as:

Wang, C., Si, Y., Abdul-Rahman, H., \& Wood, L. C. (in press). Noise annoyance and loudness: Acoustic performance of residential buildings in tropics. Building Services Engineering Research and Technology.

Table 5: Cross-tab of housing and human factors towards each type of noise

\begin{tabular}{|c|c|c|c|c|c|c|c|c|}
\hline $\begin{array}{c}\text { Annoyance } \\
\text { Rank }\end{array}$ & $\begin{array}{l}\begin{array}{l}\text { Noise } \\
\text { Type }\end{array} \\
\end{array}$ & $\begin{array}{c}\text { Facing } \\
\text { Highway }\end{array}$ & $\begin{array}{c}\text { House } \\
\text { Type }\end{array}$ & $\begin{array}{c}\text { House } \\
\text { location }\end{array}$ & $\begin{array}{c}\text { Working } \\
\text { Environment }\end{array}$ & $\begin{array}{c}\text { Job Stress } \\
\text { Level }\end{array}$ & $\begin{array}{c}\text { When } \\
\text { Distracted }\end{array}$ & $\begin{array}{c}\text { Noise } \\
\text { Sensitivity }\end{array}$ \\
\hline 1 & N_Shout & & & & & BOTH & BOTH & ANNOY \\
\hline 2 & Motorcycle & LOUD & & & & & ANNOY & BOTH \\
\hline 3 & Bus/Lorry & LOUD & LOUD & & & & ANNOY & ANNOY \\
\hline 4 & Dog & & LOUD & & & BOTH & BOTH & ANNOY \\
\hline 5 & Baby & & & & & ANNOY & & \\
\hline 6 & N_Baby & & & & & BOTH & BOTH & BOTH \\
\hline 7 & N_Door & LOUD & & & & BOTH & BOTH & ANNOY \\
\hline 8 & $\overline{\text { N_Loud TV }}$ & LOUD & & & & BOTH & BOTH & $\overline{\mathrm{BOTH}}$ \\
\hline 9 & $\overline{\mathrm{Car} / \mathrm{Van}}$ & & & & & & $\overline{\mathrm{ANNOY}}$ & ANNOY \\
\hline 10 & $\begin{array}{l}\text { Loud TV } \\
\end{array}$ & & & & & BOTH & & ANNOY \\
\hline 11 & N_Children & ANNOY & & & & BOTH & $\overline{\text { BOTH }}$ & BOTH \\
\hline$\overline{12}$ & Door & & & & & ANNOY & ANNOY & \\
\hline 13 & Children & ANNOY & & & & ANNOY & & \\
\hline 14 & N_Talk & ANNOY & & & & BOTH & BOTH & ANNOY \\
\hline 15 & N_Cough & LOUD & & & & & ANNOY & \\
\hline 16 & Rooster & & LOUD & & & LOUD & & \\
\hline 17 & Cook & ANNOY & & & & & & ANNOY \\
\hline 18 & Insect & & LOUD & LOUD & & ANNOY & & ANNOY \\
\hline 19 & Bird & & & & & ANNOY & & \\
\hline
\end{tabular}

\subsection{Post-Hoc Tests for Working Environment, Housing Type, and House Location}

The statistical relationship between independent categorical variables ("Working environment", "Housing type", and "Location of house") and dependent continuous variables ("Loudness of Noise" and "Annoyance of Noise") is provided in the Tukey HSD table of Post-hoc Tests presented in Table 6. If the significance value for Levene's test is smaller than 0.05 , the assumption of homogeneity of variance is not violated, which means the probability that the dependent variables (e.g., the loudness and annoyance of noises are) affected by the independent variables (e.g., working environment, housing type, and house location) is high. According to Table 6, the p-value for working environment to every type of noises are greater than $\mathrm{p}=0.05$, which means the working environment factor does not significantly affect the loudness and annoyance of noises. The mean loudness for bus and lorry noise is significantly different with a mean difference at 0.529 , plus the p-value is 0.048 , which means the occupants perceive a different loudness from buses and lorries, with lorries contributing much louder noise. From the Post-hoc test on dogs barking loudness against different housing types, the apartment or condominium's mean loudness for dog barking noise is significantly lower than other housing types, with a mean difference at 0.641 and p-value $=0.048$. Post-hoc tests on rooster sounds detected a significant difference between detached housing and apartment or 
This is a copy of the "Post-print" (i.e., the authors' final draft, post-refereeing). Published as:

Wang, C., Si, Y., Abdul-Rahman, H., \& Wood, L. C. (in press). Noise annoyance and loudness: Acoustic performance of residential buildings in tropics. Building Services Engineering Research and Technology.

condominium with a mean difference of 0.639 . For insect noise, detached housing performs better than terrace housing with a mean difference at 0.494 and a p-value $=0.052$. Urban housing is less affected by insect noise than suburban housing, with a p-value $=0.028$.

\subsection{Partial Least Squares Structural Equation Modeling (PLS-SEM)}

Partial Least Squares Structural Equation Modelling (PLS-SEM) was used to quantify the association among 10 latent variables: house factor, human factor, traffic Loudness, traffic annoyance, neighbor loudness, neighbor annoyance, house loudness, house annoyance, animal loudness, and animal annoyance. In the PLS-SEM diagram in Figure 7, the circles are the latent variables and the squares are the measured variables linked to these latent variables. The latent variables with only outgoing arrows are the exogenous variables, while an endogenous variable has at least one incoming arrow. The digit in a circle represents the variance of the latent variable explained by another latent variable known as coefficient of determination. Exogenous variables have a coefficient of determination at 0.000 because they are not dependent on other variables. On the other hand, an endogenous variable for example "traffic annoyance" with a coefficient of determination at 0.427 means that all latent variables pointing to it such as "house factor", "person factor", and "traffic loudness" explain $42.7 \%$ variance. The digits on the arrows are path coefficients, which explain how strong the effect of one variable is on another variable. Path coefficients can used to evaluate their relative importance. For instance in Figure 8, the path coefficients to "traffic annoyance" from "traffic loudness", "house factors", and "person factor" are (respectively) 0.602, 0.068, and 0.165, which means "traffic loudness" has the strongest influence on "traffic annoyance" among the three. A path coefficient is considered statistically significant if the value is bigger than 0.1 , thus "house factor" does not predict "traffic annoyance" directly. 
This is a copy of the "Post-print" (i.e., the authors' final draft, post-refereeing). Published as:

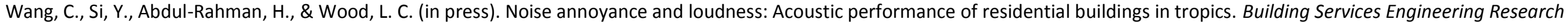
and Technology.

Table 6: Post-Hoc Tests for Working Environment, Housing Type, and House Location

\begin{tabular}{|c|c|c|c|c|c|c|c|c|c|c|c|c|}
\hline \multirow{2}{*}{ Loudness } & \multicolumn{4}{|c|}{ Working Environment } & \multicolumn{4}{|c|}{ Type of House } & \multicolumn{4}{|c|}{ House Location } \\
\hline & Sum of Squares Between Groups & Total Sum of Square & Sig. & Levene Statistic & Sum of Squares Between Groups & Total Sum of Square & Sig. & Levene Statistic & Sum of Squares Between Groups & Total Sum of Square & Sig. & Levene Statistic \\
\hline Motorcycle & 1.193 & 126.222 & 0.662 & 0.419 & 2.125 & 126.222 & 0.416 & 0.001 & 0.715 & 126.222 & 0.621 & 0.002 \\
\hline Car/Van & 0.720 & 96.082 & 0.739 & 0.262 & 3.856 & 96.082 & 0.076 & 0.026 & 0.018 & 96.082 & 0.985 & 0.477 \\
\hline Bus/Lorry & 1.066 & 149.24 & 0.753 & 0.566 & 7.101 & 149.24 & 0.043 & 0.162 & 0.210 & 149.24 & 0.889 & 0.719 \\
\hline N_Talk & 1.761 & 124.047 & 0.494 & 0.901 & 0.643 & 124.047 & 0.833 & 0.037 & 0.471 & 124.047 & 0.727 & 0.616 \\
\hline N_Shout & 4.77 & 169.684 & 0.189 & 0.099 & 3.215 & 169.684 & 0.361 & 0.043 & 1.379 & 169.684 & 0.504 & 0.736 \\
\hline N_Children & 1.673 & 115.415 & 0.485 & 0.375 & 1.454 & 115.415 & 0.547 & 0.624 & 0.571 & 115.415 & 0.660 & 0.829 \\
\hline N_Baby & 1.901 & 140.994 & 0.518 & 0.948 & 1.696 & 140.994 & 0.567 & 0.122 & 1.586 & 140.994 & 0.387 & 0.128 \\
\hline N_Cough & 1.337 & 100.292 & 0.522 & 0.904 & 1.008 & 100.292 & 0.639 & 0.249 & 0.604 & 100.292 & 0.602 & 0.554 \\
\hline N_LoudTV & 3.153 & 151.684 & 0.318 & 0.778 & 2.422 & 151.684 & 0.441 & 0.273 & 3.101 & 151.684 & 0.176 & 0.432 \\
\hline N_Door & 2.072 & 150.737 & 0.509 & 0.830 & 4.685 & 150.737 & 0.152 & 0.558 & 1.478 & 150.737 & 0.437 & 0.657 \\
\hline Cook & 0.888 & 64.047 & 0.505 & 0.054 & 0.146 & 64.047 & 0.944 & 0.479 & 0.565 & 64.047 & 0.475 & 0.299 \\
\hline Baby & 4.729 & 120.643 & 0.082 & 0.731 & 2.856 & 120.643 & 0.260 & 0.286 & 0.660 & 120.643 & 0.631 & 0.472 \\
\hline LoudTV & 0.649 & 110.678 & 0.805 & 0.121 & 1.852 & 110.678 & 0.419 & 0.001 & 1.328 & 110.678 & 0.363 & 0.007 \\
\hline Door & 0.660 & 113.789 & 0.807 & 0.266 & 0.272 & 113.789 & 0.940 & 0.610 & 1.389 & 113.789 & 0.356 & 0.172 \\
\hline Dog & 2.617 & 185.158 & 0.496 & 0.310 & 10.405 & 185.158 & 0.021 & 0.304 & 1.123 & 185.158 & 0.600 & 0.936 \\
\hline Rooster & 4.139 & 108.632 & 0.089 & 0.072 & 7.234 & 108.632 & 0.009 & 0.277 & 8.819 & 108.632 & 0.001 & 0.000 \\
\hline Bird & 1.561 & 82.327 & 0.361 & 0.709 & 3.577 & 82.327 & 0.059 & 0.082 & 0.819 & 82.327 & 0.432 & 0.795 \\
\hline Insect & 0.157 & 91.684 & 0.962 & 0.528 & 4.781 & 91.684 & 0.030 & 0.771 & $\begin{array}{ll}4.447 \\
\end{array}$ & 91.684 & 0.015 & 0.343 \\
\hline \multirow{2}{*}{ Annoyance } & \multicolumn{4}{|c|}{$\begin{array}{l}\text { Working Environment } \\
\text { S }\end{array}$} & \multirow{2}{*}{\multicolumn{4}{|c|}{$\begin{array}{l}\text { Type of House } \\
\text { Total Sum of Square }\end{array}$}} & \multicolumn{4}{|c|}{ House Location } \\
\hline & Sum of Squares Between Groups & Total Sum of Square & Sig. & Levene Statistic & & & Sig. & & Sum of Squares Between Groups & Total Sum of Square & Sig. & Levene Statistic \\
\hline CL_Motorcycle & 2.172 & 186.947 & 0.581 & 0.858 & 1.459 & 186.947 & 0.726 & 0.304 & 0.524 & 186.947 & 0.790 & 0.357 \\
\hline CL_Car/Van & 2.084 & 129.789 & 0.438 & 0.235 & 4.065 & 129.789 & 0.149 & 0.012 & 1.396 & 129.789 & 0.403 & 0.334 \\
\hline CL_Bus/Lorry & 0.880 & 148.713 & 0.803 & 0.086 & 2.137 & 148.713 & 0.489 & 0.028 & 0.212 & 148.713 & 0.887 & 0.504 \\
\hline CL_N_Talk & 0.317 & 116.749 & 0.929 & 0.429 & 0.287 & 116.749 & 0.938 & 0.322 & 0.202 & 116.749 & 0.865 & 0.922 \\
\hline CL_N_Children & 0.953 & 116.749 & 0.712 & 0.474 & 0.488 & 116.749 & 0.873 & 0.408 & 0.394 & 116.749 & 0.753 & 0.790 \\
\hline CL_N_Baby & 2.525 & 145.626 & 0.403 & 0.034 & 2.994 & 145.626 & 0.323 & 0.181 & 0.115 & 145.626 & 0.936 & 0.957 \\
\hline CL_N_Cough & 2.628 & 87.836 & 0.166 & 0.036 & 0.285 & 87.836 & 0.909 & 0.322 & 1.569 & 87.836 & 0.220 & 0.059 \\
\hline CL_N_LoudTV & 3.548 & 144.526 & 0.244 & 0.243 & 4.353 & 144.526 & 0.163 & 0.016 & 0.658 & 144.526 & 0.682 & 0.917 \\
\hline CL_N_Door & 1.426 & 152.187 & 0.665 & 0.970 & 3.564 & 152.187 & 0.265 & 0.040 & 2.823 & 152.187 & 0.207 & 0.674 \\
\hline CL_Cook & 0.254 & 57.158 & 0.862 & 0.700 & 0.624 & 57.158 & 0.607 & 0.067 & 0.482 & 57.158 & 0.491 & 0.039 \\
\hline CL_Children & 1.929 & 94.105 & 0.325 & 0.163 & 1.614 & 94.105 & 0.408 & 0.084 & 2.115 & 94.105 & 0.148 & 0.001 \\
\hline CL_Baby & 1.316 & 110.632 & 0.571 & 0.641 & 2.451 & 110.632 & 0.290 & 0.001 & 0.999 & 110.632 & 0.467 & 0.074 \\
\hline CL_LoudTV & 2.690 & 112.947 & 0.257 & 0.396 & 4.746 & 112.947 & 0.066 & 0.042 & 0.770 & 112.947 & 0.563 & 0.837 \\
\hline CL_Door & 1.415 & 123.836 & 0.588 & 0.561 & 1.192 & 123.836 & 0.655 & 0.322 & 0.890 & 123.836 & 0.546 & 0.287 \\
\hline CL_Dog & 3.231 & 178.678 & 0.383 & 0.063 & 8.002 & 178.678 & 0.053 & 0.010 & 0.347 & 178.678 & 0.849 & 0.378 \\
\hline CL_Rooster & 0.741 & 67.684 & 0.605 & 0.127 & 0.859 & 67.684 & 0.544 & 0.042 & 1.019 & 67.684 & 0.280 & 0.031 \\
\hline CL_Bird & 0.073 & 40.737 & 0.960 & 0.752 & 0.916 & 40.737 & 0.283 & 0.003 & 0.117 & 40.737 & 0.785 & 0.443 \\
\hline CL_Insect & 0.414 & 57.240 & 0.749 & 0.147 & 2.031 & 57.240 & 0.109 & 0.000 & 0.020 & 57.240 & 0.971 & 0.886 \\
\hline
\end{tabular}


These results show a small percentage of variance of loudness is explained by other factors; e.g., only $10.7 \%$ neighbor noises depend on housing and human factors. Compared to "loudness of noises", "annoyance of noises" is more dependent on other variables; e.g., the perception of the annoyance of $69.7 \%$ of animal noises is influenced by other factors. Although the perception of the annoyance of "traffic noises" has the least dependence on other factors, $42.7 \%$ of its variance is explained by other variables. For the loudness of "traffic noises", "neighbor noises", and "own house noises", human factors have stronger influence than house factors, but the loudness of "animal noises" is influenced more by house factors than by human factors.

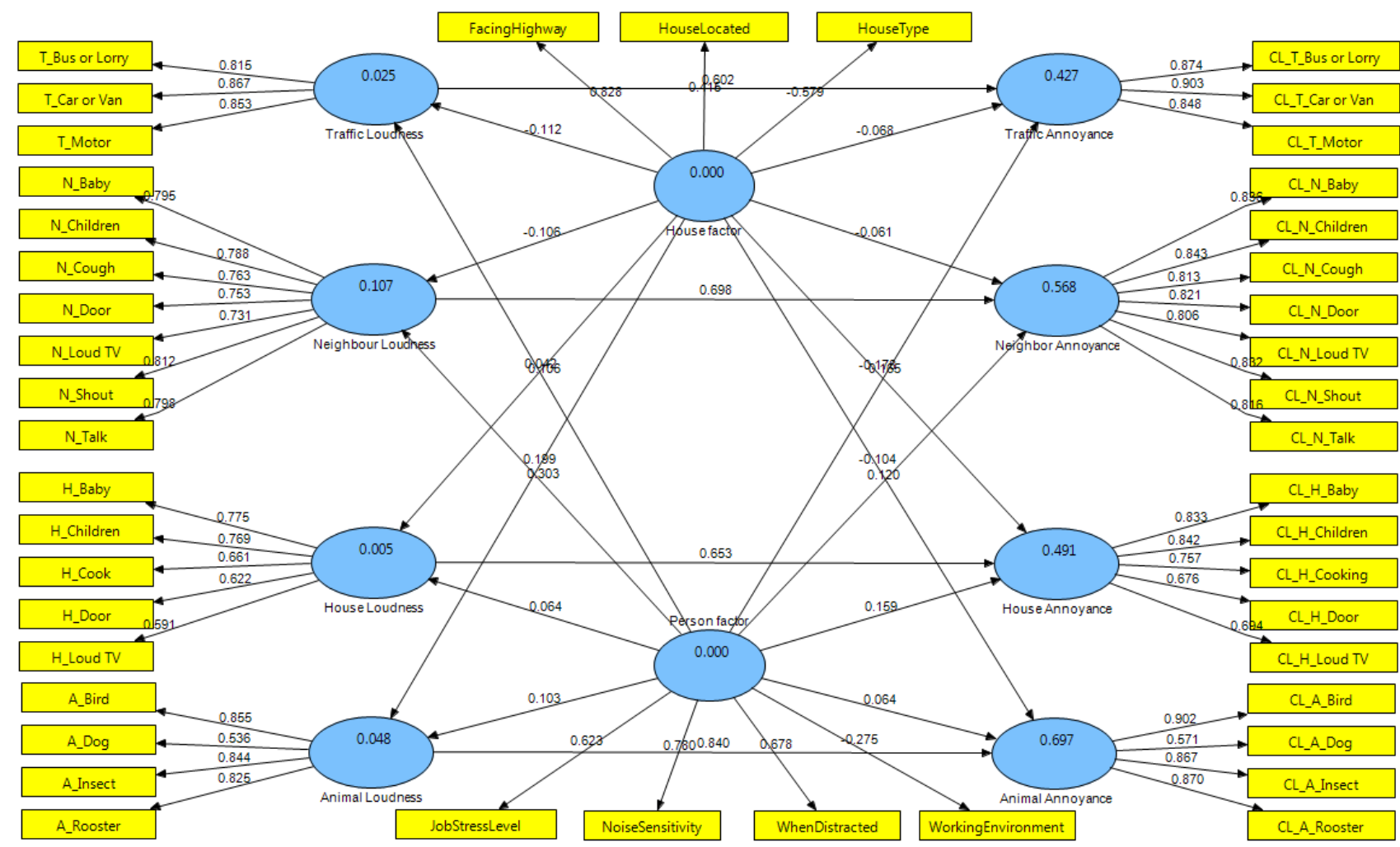

Figure 8: Partial Least Squares Structural Equation Modeling

\subsection{Discussion on Findings}


This is a copy of the "Post-print" (i.e., the authors' final draft, post-refereeing). Published as:

Wang, C., Si, Y., Abdul-Rahman, H., \& Wood, L. C. (in press). Noise annoyance and loudness: Acoustic performance of residential buildings in tropics. Building Services Engineering Research and Technology.

Although both Jakovljevic et al. (2009) ${ }^{16}$ and Paunovic et al. (2009) ${ }^{24}$ found construction noise is a

very annoying noise, this was excluded from this research as this is not a continuous noise around residential buildings. Importantly, construction work is not conducted at construction sites after office hours in Malaysia and therefore the construction noise does not affect the life of working people after they return home from work. Some animal noises such as bird calls might be perceived as a positive noise by some people as supported by Ratcliffe et al. (2013) ${ }^{25}$; but Ratcliffe et al. (2013) pointed out that some birds, such as magpies and crows, are often considered very annoying ${ }^{25}$. However, noise from barking dogs is generally agreed by scholars as having a negative impact on occupants. The most annoying noises in this study are traffic noise and neighborhood noise. These results agree with the studies of Jakovljevic et al. (2009) ${ }^{16}$, Paunovic (2009), and Zannin and Bunn $(2014)^{2}$. PLS-SEM found the loudness and annoyance of noise are highly inter-correlated. This is easy to understand because a loud noise tends to be more annoying. ${ }^{12}$ The occupants in apartments ranked motorcycle noise as the most annoying but not the loudest traffic noise, and the loudest traffic noise is from buses and lorry. On the other hand, occupants in landed properties ranked the motorcycle noise as the loudest but not the most annoying noise. This might be due to the loudest noises in apartments still coming from neighbors while landed properties are closer to the motorcycles (as a noise source) as suggested by Méline et al. (2013). ${ }^{26}$ For neighbor's noises, although none are significantly affected by the housing type, the trend can be observed that generally apartments have the loudest neighbor noise followed by terrace house and semi-detached house. Detached houses are hardly affected by neighbor noise. Door banging, as a structure borne noise, is more annoying in apartments than that in other three housing types. Lee et al. (2010) explains that neighbor noise can easily transmit into the occupant's unit via structure borne or airborne methods, but detached houses are not attached to neighboring unit thus they can be spared. ${ }^{20}$ Detached house also has the lowest noise from own house compared to other housing types. The reason might be due to the fact that they tend to have the largest floor area and therefore the source of noise might be 
This is a copy of the "Post-print" (i.e., the authors' final draft, post-refereeing). Published as:

Wang, C., Si, Y., Abdul-Rahman, H., \& Wood, L. C. (in press). Noise annoyance and loudness: Acoustic performance of residential buildings in tropics. Building Services Engineering Research and Technology.

further from the respondent. Generally, detached houses have larger floor area than semi-detached houses. Terrace houses are usually constructed as medium- or low-cost housing, while apartments generally have the smallest floor area. The analysis on human-related factors shows job stress and occupants' sensitivity to noise are highly correlated with many types of noises. The influence of human-related factors are more significant compared to the housing-related factors as agreed by Jakovljevic et al. (2009) ${ }^{16}$ and Paunović et al. (2009). ${ }^{24}$ In contrast to Crociata et al. $(2013)^{9}$, this research did not find any significant association between occupants' working environment and their perception on noises.

It is also important to interpret the results in light of different cultural expectations regarding acoustic comfort in different regions of the world. In some cultures pets are more common than others, and so dog barking noises may be more common. In wealthier, first-world nations, housing stock investments may be significantly greater as residences may be either further from highways or are provided with additional acoustic insulation. Such design considerations may reduce the impact of traffic noise.

This study will directly assist building developers and architects to enhance the acoustic properties of residential buildings. Potential property buyers will have a guide to examining the acoustic performance of the building they are going to purchase and dwell in. All types of audible noises annoying residents in full range of residential buildings in tropics were identified and categorized. The loudness and annoyance of each type of noise to residents or occupants were benchmarked. The physical and psychological impact of noise loudness and annoyance to the occupants living in different types of residential buildings were determined and mapped. The results will inform improved industry standards and the extended findings of this research are expected to cover the acoustic performance of office buildings, shopping complexes, and warehouses. 


\subsection{Conclusion and Recommendations}

This research aimed to identify all types of noises in a range of residential buildings and to determine the impact on occupants, accounting for loudness and annoyance levels. We found that traffic noises are the most undesired noise, followed by the noises from neighbors. More interestingly, the annoyance of traffic noises and neighbor's noises are inter-correlated. Occupants who suffer from louder neighbor noises also suffer from louder traffic noises. Animal noises such as birds chirping, rooster calls, and insects noise basically create little annoyance to occupants, but barking dogs have significant impact on annoyance. Job stress and occupants' sensitivity to noise are highly correlated with many types of noises. The influence of human-related factors is significant compared to the housing-related factors. However, choosing an appropriate housing type can decrease the loudness and annoyance of certain noises; e.g., traffic and neighbor noises. Apartments in high rise buildings thus have a higher chance to receive traffic noises if they face the highway. In contrast, terrace houses are usually constructed densely in big residential areas and thus most units are spared from traffic noises. However, densely packed terrace houses have the greatest exposure to dogs barking, while apartment residents are not annoyed by dogs barking because of the dog control exerted by their maintenance offices. Urban houses have higher bus and lorry noises but less motorcycle noises compared to those suburban and rural houses. The rural houses suffer more from motorcycle, car, and van noises. Future research will be assisted by sound meters and those significant noise types found in the partial least squares structural equation modeling will be measured in terms of decibels and frequency to further quantify their physical and psychological impacts on humans.

The study has been necessarily limited in two ways. First, the method that we used is a questionnaire which captures the perception of noise loudness and annoyance. This does not measure the actual 
This is a copy of the "Post-print" (i.e., the authors' final draft, post-refereeing). Published as:

Wang, C., Si, Y., Abdul-Rahman, H., \& Wood, L. C. (in press). Noise annoyance and loudness: Acoustic performance of residential buildings in tropics. Building Services Engineering Research and Technology.

volume in decibels or the frequency of noise, although these can be important factors. These were not measured as it would require specialized equipment at the residence of each respondent and it fails to capture the occupants' subjective experience of the noise. As the research covered the entire country of Malaysia, use of equipment within the homes exceeded the financial support of the project. Second, the data were collected from across Malaysia and will reflect attitudes and beliefs of the people experiencing life in this region; therefore, the results may not be generalized beyond Malaysia or other developing nations. The reason for this is that cross-cultural perceptions and attitudes towards different types of noise may exist. As an example, pet ownership rates differ between countries and so in some countries dog barks may be more common than in others and there may be different levels of toleration of this particular noise amongst the population of different countries. Therefore, generalizing beyond other developing nations in the tropics (i.e., with similar animals and insect life) should be undertaken with care.

\section{Acknowledgement:}

Authors are thankful to Ministry of Higher Education Malaysia for financial support through Fundamental Research Grant Scheme FP052-2014B.

\section{REFERENCES}

1 Huang YC, Chu CL, Chang LSN, Lan SJ, Hsieh CH, Hsieh YP. Building users' perceptions of importance of indoor environmental quality in long-term care facilities. Building and Environment 2013; 67: 224-230.

2 Zannin PHT, Bunn F. Noise annoyance through railway traffic: A case study. Journal of Environmental Health Science and Engineering 2014; 12: 14-15. 
This is a copy of the "Post-print" (i.e., the authors' final draft, post-refereeing). Published as:

Wang, C., Si, Y., Abdul-Rahman, H., \& Wood, L. C. (in press). Noise annoyance and loudness: Acoustic performance of residential buildings in tropics. Building Services Engineering Research and Technology.

3 Urban J, Máca V. Linking traffic noise, noise annoyance and life satisfaction: a case study.

International Journal Of Environmental Research And Public Health 2013; 10(5): 1895-915.

4 Wang B, Kang J. Effects of urban morphology on the traffic noise distribution through noise mapping: A comparative study between UK and China. Applied Acoustics 2011; 72(8): 556-568.

5 Croome DJ. Noise, Buildings and People,1st ed. Headington: Pergamon Press Ltd., 1977.

6 van de Poll MK, Ljung R, Odelius J, Sörqvist P. Disruption of writing by background speech: The role of speech transmission index. Applied Acoustics 2014; 81: 15-18.

7 Frontczak M, Wargocki P. Literature survey on how different factors influence human comfort in indoor environments. Building and Environment 2011; 46(4): 922-937.

8 Kuerer RC. Classes of Acoustical Comfort in Housing: Improved Information about Noise Control in Buildings. Applied Acoustics 1997; 52(3/4): 197-210.

9 Crociata SD, Simone A, Martellotta F. Acoustic comfort evaluation for hypermarket workers. Building and Environment 2013; 59: 369-378.

10 Yusoff S, Ishak A. Study On An Evaluation Of Urban Highway Environmental Noise Pollution: A Malaysian Case Study. Sains Malaysiana 2005; 34(2): 81-87.

11 Commins DE, Meier AV. Classes of acoustical comfort in housing. Classes of Acoustical Comfort in Housing 1978; Report No. 7r. EEC Commission, Brussels.

12 Lundquist P, Holmberg K, Landstrom U. Annoyance and effects on work from environmental noise at school. Noise \& Health 2000; 2(8): 39-46.

13 Williams ID, McCrae IS. Road traffic nuisance in residential and commercial areas. The Science Of The Total Environment 1995; 169(1-3): 75-82.

14 Xie H, Kang J, Tompsett R. The impacts of environmental noise on the academic achievements of secondary school students in Greater London. Applied Acoustics 2011; 72(8): 551-555. 
This is a copy of the "Post-print" (i.e., the authors' final draft, post-refereeing). Published as:

Wang, C., Si, Y., Abdul-Rahman, H., \& Wood, L. C. (in press). Noise annoyance and loudness: Acoustic performance of residential buildings in tropics. Building Services Engineering Research and Technology.

15 Zannin PHT, Calixto A, Diniz FB, Ferreira JAC. A survey of urban noise annoyance in a large

Brazilian city: the importance of a subjective analysis in conjunction with an objective analysis.

Environmental Impact Assessment Review 2003; 23(2): 245-255.

16 Jakovljevic B, Paunovic K, Belojevic G. Road-traffic noise and factors influencing noise annoyance in an urban population. Environment International 2009; 35(3): 552-556.

17 Muller G, Moser M. Handbook of Engineering Acoustics. New York: Springer, 2013.

18 Lawrence A. Architectural Acoustics, 1st eds. New York: Elsevier Publishing Company Limited, 1970.

19 Phan HYT, Yano T, Phan HAT, Nishimura T, Sato T, Hashimoto Y. Community responses to road traffic noise in Hanoi and Ho Chi Minh City. Applied Acoustics 2010; 71(2): 107-114.

20 Lee PJ, Jeon JY, Shim MH. Effects of different noise combinations on sleep, as assessed by a general questionnaire. Applied Acoustics 2010; 71(9): 870-875.

21 De Kluizenaar Y, Janssen SA, Vos H, Salomons EM, Zhou H, van den Berg F. Road traffic noise and annoyance: a quantification of the effect of quiet side exposure at dwellings. International journal of environmental research and public health 2013; 10(6): 2258-2270.

23 Laussmann D, Haftenberger M, Lampert T, Scheidt-Nave C. Social inequities regarding annoyance to noise and road traffic intensity: results of the German Health Interview and Examination Survey for Adults (DEGS1). Bundesgesundheitsblatt, Gesundheitsforschung, Gesundheitsschutz 2013; 56(5-6): 822-831.

24 Paunović K, Jakovljević B, Belojević G. Predictors of noise annoyance in noisy and quiet urban streets. The Science of the total environment 2009; 407(12): 3707-3711.

25 Ratcliffe E, Gatersleben B, Sowden PT. Bird sounds and their contributions to perceived attention restoration and stress recovery. Journal of Environmental Psychology 2013; 36: 221-228. 
This is a copy of the "Post-print" (i.e., the authors" final draft, post-refereeing). Published as:

Wang, C., Si, Y., Abdul-Rahman, H., \& Wood, L. C. (in press). Noise annoyance and loudness: Acoustic performance of residential buildings in tropics. Building Services Engineering Research and Technology.

26 Méline J, van Hulst A, Thomas F, Karusisi N, Chaix B. Transportation noise and annoyance

related to road traffic in the French record study. International Journal Of Health Geographics 2013;

12: 44-45.

\section{Figure Legends}

Figure 1: Loudness and Annoyance of Noises

Figure 2: Traffic Noise and Housing Type

Figure 3: Neighbor Noise and Housing Type

Figure 4: Animal Noises and Housing type

Figure 5: Neighbor Noises and House Location

Figure 6: Noises affected by facing highway

Figure 7: Neighbor Noises and Occupants' sensitivity on noise

Figure 8: Partial Least Squares Structural Equation Modeling 